\title{
Atypical leptospirosis: an overlooked cause of aseptic meningitis
}

\author{
Ning Wang ${ }^{1}$, Yu-Hsuan Han ${ }^{1}$, Jia-Ying Sung ${ }^{1}$, Wen-Sen Lee ${ }^{2}$ and Tsong-Yih Ou²
}

\begin{abstract}
Background: Leptospirosis, probably the most common zoonosis in the world, is caused by pathogenic Leptospira species. Clinical presentations range from nonspecific fevers to fulminant diseases such as Weil's syndrome. Neurological forms of leptospirosis (neuroleptospirosis) are usually underestimated, and many cases of leptospirosis are overlooked because of the lack of specificity of signs and symptoms. Diagnosis confirmation is difficult because of the challenges associated with isolating the organism and positive serologic testing. A comprehensive understanding of the clinical presentation of leptospirosis and risk factors for exposure to leptospirae are required for early diagnosis, in order to initiate appropriate treatment immediately.

Case presentation: Here we present one male patient with anicteric leptospirosis that manifested as neuroleptospirosis with aseptic meningitis, although he did not have impaired kidney function or thrombocytopenia. He recovered well after an early investigation and treatment for leptospirosis based on suspected relevant risk factors and clinical manifestations.
\end{abstract}

Conclusion: To facilitate optimal use of antibiotic treatments and prevent lethal complications of leptospirosis, we report this case of leptospirosis, which highlights the importance of knowing the occupational history and environmental exposures of patients living in leptospirosis-endemic areas and presenting meningeal signs.

Keywords: Leptospirosis, Leptospira, Aseptic meningitis, Neuroleptospirosis, Zoonosis

\section{Background}

Leptospirosis is an acute febrile zoonotic disease caused by infection with pathogenic spirochetes of the genus Leptospira. It is transmitted to humans principally via environmental water contaminated with the urine of wild and domestic mammals that are chronically colonized by Leptospira [1]. The leptospires dwell in the renal tubules of their animal hosts, including almost all known species of rodents, marsupials and other mammals, which are common carriers and excretors of leptospires [2]. Risk of infection is associated with occupational and recreational activities, as well as household environments where there is close contact with animals. The clinical presentations are diverse, ranging from undifferentiated fever to fatal

\footnotetext{
*Correspondence: 93023@w.tmu.edu.tw

2 Division of Infectious Diseases, Department of Internal Medicine, Wan Fang Medical Center, Taipei Medical University, No. 111, Section. 3, Shing Long Road, Taipei 11696, Taiwan

Full list of author information is available at the end of the article
}

disease. Anicteric leptospirosis is the most common manifestation, occurring in $80 \%$ of cases [3]. Its diagnosis relies upon a strong suspicion of this disease based on various nonspecific clinical presentations. This worldwide disease has been found to occur predominantly in wet tropical and subtropical regions $[4,5]$, including Taiwan. Here, we describe a male patient with leptospirosis, who presented with aseptic meningitis but without jaundice, impaired kidney function or thrombocytopenia. The patient was prudently investigated and treated based on his relevant exposure history and clinical manifestations.

\section{Case report}

The 37-year-old male patient was a cook working in a restaurant close to a waste recycling station and a pond for recreational shrimp fishing. The patient was generally healthy and had suffered no major illnesses until 1 week before hospitalization. At that time, in late November 2012 (autumn), he presented with a low grade fever, 
nausea, and vomiting, which subsided rapidly within 2 days after taking prescription medicines containing no antibiotics or nonsteroidal anti-inflammatory drugs. He returned to work shortly thereafter, but soon the abrupt onset of persistent diffuse headaches and a sensation of fullness resulted in disturbed sleep. He experienced unrelenting vomiting, and in addition he recalled that he had persistent neck stiffness, even when he lay down. He was then admitted to the emergency unit, at which time his blood pressure was $129 / 77 \mathrm{mmHg}$, body temperature was $37^{\circ} \mathrm{C}$, pulse rate was 93 beats/min, and respiratory rate was 20 times $/ \mathrm{min}$. The physical examination showed that he had an alert, distressed facial appearance, with anicteric sclerae and a supple neck without lymphadenopathy. He did not have any neurologic deficits or skin abnormalities. He did not show any abnormalities in other system examinations. The patient denied any history of recent travel, but mentioned that his working environment was infested with rats, which ran through the kitchen in the daytime.

The initial laboratory examination of peripheral blood showed that his serum haemoglobin level was $15.7 \mathrm{~g} /$ $\mathrm{dl}$, platelet count was 338,000 cells/ $\mu \mathrm{l}$, white blood cell (WBC) count was 18,670 cells/ $\mu$ l with $81.2 \%$ segmented neutrophils and $14.1 \%$ lymphocytes, his $C$-reactive protein was $20 \mathrm{mg} / \mathrm{dl}$, creatinine was $1.03 \mathrm{mg} / \mathrm{dl}$, aspartate aminotransferase (AST) was $34 \mathrm{IU} / \mathrm{l}$, and glucose was $117 \mathrm{mg} / \mathrm{dl}$. The initial lumbar puncture revealed an opening pressure of $24 \mathrm{cmH}_{2} \mathrm{O}$. The cerebrospinal fluid (CSF) tested negative for the cryptococcal antigen test and India Ink test, and had a WBC of 254 cells/ $\mu$ l comprising $91 \%$ mononuclear cells and $9 \%$ segmented neutrophils, a red blood cell count (RBC) of 36 cells/ $\mu \mathrm{l}$, total protein of $91 \mathrm{mg} / \mathrm{dl}$, and glucose of $64 \mathrm{mg} / \mathrm{dl}$. Based on these initial laboratory results, the patient received $2 \mathrm{~g}$ of ceftriaxone $\mathrm{q} 12 \mathrm{~h}$ and $500 \mathrm{mg}$ of acyclovir q8h for meningitis, including aseptic meningitis.

Despite the identification and treatment of aseptic meningitis, his clinical condition did not improve. He was further investigated for other pathogens that might cause aseptic meningitis. Upon re-evaluation of his clinical presentations, with a focus on his occupation and hobby of shrimp fishing, the causal pathogen was suspected to be microbes that could cause CSF pleocytosis, apparently as a result of aseptic meningitis. After undergoing additional tests for atypical pathogens in the serum, such as the latex agglutination test for cryptococcal antigen, particle agglutination assay for IgG and IgM antibodies to Mycoplasma pneumonia, and an electrochemiluminescence immunoassay for IgG and IgM antibodies to Toxoplasma gondii, he received additional minocycline, ampicillin and steroids for his unremitting increased intracranial pressure-induced headache and vomiting.
His clinical symptoms improved markedly after day two. The follow-up lumbar puncture on hospital day four revealed an opening pressure of $23.6 \mathrm{cmH}_{2} \mathrm{O}$, a WBC of 266 cells/ $\mu$ l comprising $99 \%$ mononuclear cells, a RBC of $141 \mathrm{cells} / \mu \mathrm{l}$, total protein of $33 \mathrm{mg} / \mathrm{dl}$, and glucose level of $78 \mathrm{mg} / \mathrm{dl}$, compared with a serum glucose level of $141 \mathrm{mg} /$ dl. Other follow-up laboratory test results were unremarkable, except for a WBC of 14,840 cells/ $\mu$ l with $83 \%$ segmented neutrophils and $12 \%$ lymphocytes. Ceftriaxone was discontinued, despite no evidence of pneumococcus or enteric rods. The aforementioned serological tests for atypical pathogens revealed negative results for Cryptococcus, mycoplasma and toxoplasma. The particle agglutination assay for HIV antibody in the serum sample and the polymerase chain reaction (PCR) method for detecting tuberculosis and the herpes simplex virus also showed negative findings. The Taiwan Centers for Disease Control laboratory performed an indirect immunofluorescence assay for Q fever, scrub typhus and epidemic typhus with paired serum samples, and PCR testing of whole blood samples. These samples were collected on hospital days 2 and 16.

Acyclovir was discontinued on hospital day 10, since there was no evidence of a herpes simplex viral infection. On hospital day 14, the patient's third lumbar puncture showed an opening pressure of $18 \mathrm{cmH}_{2} \mathrm{O}$, a WBC of 49 cells/ $\mu$ l with $99 \%$ mononuclear cells, a RBC of 1 cell/ $\mu \mathrm{l}$, total protein of $32 \mathrm{mg} / \mathrm{dl}$, and a glucose level of $81 \mathrm{mg} /$ $\mathrm{dl}$, compared with a serum glucose level of $153 \mathrm{mg} / \mathrm{dl}$.

The patient was discharged on hospital day 16 after being treated with minocycline and ampicillin for 14 days. On the day after discharge, we received confirmation from the Taiwan Centers for Disease Control of the diagnosis of leptospirosis via a microscopic agglutination test (MAT), with convalescent titers of $L$. interrogans serovar bataviae and $L$. santarosai serovar Shermanii at a 1:100 dilution and a 1:800 dilution, respectively, although the titers were both negative in the initial acute phase. The patient was therefore diagnosed as having been infected by $L$. santarosai serovar Shermanii with meningitis.

\section{Discussion}

We have presented the case of a male patient with a mild form of leptospirosis. The interesting aspect of this patient was an isolated central nervous system involvement, in the form of aseptic meningitis. He did not show any of the other more common symptoms of leptospirosis, such as myalgia, conjunctival suffusion, jaundice, thrombocytopenia, or abnormalities in the hepatic or renal functions. The rat infestation at his workplace was the only clue, in addition to a strong suspicion of this zoonotic disease, that allowed us to distinguish it from common viral meningitis. 
Leptospirosis in humans is acquired through contact with the urine or tissues of an infected animal, or through contaminated water and soil [5]. Rodents are recognized as the most important sources of the transmission of leptospirosis [5]. Risk factors for exposure to leptospirae include occupational exposure (farmers and ranchers, abattoir workers, trappers, veterinary surgeons, loggers, sewer workers, rice-field workers and military personnel), recreational activities (freshwater swimming, canoeing and kayaking, trail biking and hunting) and household environmental factors (domestic dogs and livestock, rainwater catchment systems and rodent infestations) [4].

During the bacteraemic phase, leptospires can be cultured from the blood, CSF, and other tissues, but not from urine [6]. Leptospiruria can persist in humans for 1-3 weeks, and in some animals leptospires can be shed chronically [7]. During the immune phase, lymphocytic pleocytosis occurs, with total cell counts usually below 500 cells $/ \mu \mathrm{l}$, and diagnosis can be made through immunological tests [7]. In this later phase, the CSF is characterized by protein levels of $50-100 \mathrm{mg} / \mathrm{dl}$ and generally normal glucose concentrations [7].

As stated previously, aseptic meningitis with or without symptoms is characteristic of the immune phase of the illness, occurring in up to $80 \%$ of patients [7]. In endemic areas, a significant proportion of all aseptic meningitis cases may be caused by leptospiral infection [7]. Severe neurologic complications, such as coma, meningoencephalitis, hemiplegia, transverse myelitis or Guillain-Barré syndrome, occur only rarely $[5,7]$. Leptospirosis is responsible for $5-13 \%$ of all cases of aseptic manifestations, including hemiplegia, intracranial bleeding, cerebellitis, movement disorders, myelitis, and acute flaccid paralysis such as Guillain-Barré syndrome, mononeuritis, facial palsy, and neuralgias [8]. Meningeal signs occur in $80 \%$ of cases [7], but leptospirosis rarely manifests primarily as a neurological disease [9]. Wang et al. [10] reported a case of a 44-year-old male leptospirosis patient who presented with neuroleptospirosis with transient paraparesis, thrombocytopenia, mild elevated aminotransferase, mild bilirubinemia (total bilirubin $2.0 \mathrm{mg} / \mathrm{dl}$ ) and mild impaired kidney function (serum creatinine $2 \mathrm{mg} / \mathrm{dl}$ ), but without meningitis. Our patient, who had risk factors associated with exposure to rats and his occupation as a cook, presented with aseptic meningitis with normal liver and kidney function. Our CSF culture showed no growth, which could be explained by a recall bias for the exact time of symptom onset. However, since we strongly suspected leptospirosis, we prudently investigated that possibility and treated him, and he recovered well without sequelae.
Taiwan lies in the path of many tropical storms and typhoons, which bring extremely heavy rainfall, usually in July-September. The mean annual incidence of leptospirosis is 0.21 cases $/ 100,000$ people [11]. The major serotype thus far identified has been $L$. santarosai serovar Shermanii $[11,12]$. Acute disseminated encephalomyelitis has rarely been reported following leptospirosis [13]. In cases of aseptic meningitis occurring in areas with endemic leptospirosis, using a modified Faine's criteria score in a preliminary evaluation of the patient [14] may be helpful for further treatment decisions and in investigating the possibility of leptospirosis. Magnetic resonance imaging (MRI) is a good method for identifying acute disseminated encephalomyelitis [13]. Our case was only evaluated via computed tomography $(\mathrm{CT})$, so we could not confirm or exclude encephalitis.

The present case was diagnosed as neuroleptospirosis based on CSF pleocytosis and positive MAT results for acute and convalescent serum. We were fortunate to obtain a positive result for the paired serum using the MAT serology method. Several recent publications reveal that the molecular methods for detecting nucleic acids have improved in diagnostic sensitivity. A quantitative PCR targeting the pathogenic Leptospira-specific 16S ribosomal RNA gene was found to be a promising tool for the rapid diagnosis of acute leptospirosis, with a wide temporal window for the detection of positive results [15]. The Lepto-MD assay, which targets the Leptospira $16 \mathrm{~S}$ rrs gene and can be performed as a real-time RT-PCR, has demonstrated an increased sensitivity in Leptospira detection. This molecular method shows virtually no overlap with the single-specimen MAT serology method, and a combined testing strategy for acute leptospirosis could maximize case detection [16].

Two cases have been diagnosed with neuroleptospirosis based on Leptospira DNA that was detected in the CSF. In one of these two patients, the DNA was detected only in the CSF, in the absence of leptospiremia [17]. Unbiased next-generation sequencing of the CSF and serum was used to diagnose primary neuroleptospirosis of Leptospira santarosai in a 14-year-old boy with severe combined immunodeficiency (SCID), who had received a bone marrow transplant. He was not diagnosed over a period of 4 months, during which he experienced progressively worse symptoms, including hydrocephalus and status epilepticus, until the next-generation sequencing method detected Leptospira DNA in his CSF but not in his serum. This approach thus facilitated the use of targeted and efficacious antimicrobial therapy [18].

\section{Conclusion}

In order to facilitate optimal use of antibiotic treatment and prevent the lethal complications of leptospirosis, 
we have reported this case of a patient with leptospirosis, because it highlights the importance of knowing the occupational history and environmental exposures of patients living in leptospirosis-endemic areas, who present with meningeal signs.

\section{Consent}

Written informed consent was obtained from the patient for publication of this case report and any accompanying images.

\section{Abbreviations}

AST: aspartate aminotransferase; CSF: cerebrospinal fluid; CT: computed tomography; MAT: microscopic agglutination test; MRI: magnetic resonance imaging; PCR: polymerase chain reaction; RBC: red blood cell; WBC: white blood cell.

\section{Authors' contributions}

NW, TYO, and YHH participated in the management of the patient. NW and TYO drafted the manuscript. TYO, JYS, and WSL contributed the consultation for medical care. NW, TYO and JYS revised the preliminary manuscript. All authors read and approved the final manuscript.

\section{Author details}

${ }^{1}$ Department of Neurology, Wan Fang Medical Center, Taipei Medical University, No. 111, Section. 3, Shing Long Road, Taipei 11696, Taiwan. ${ }^{2}$ Division of Infectious Diseases, Department of Internal Medicine, Wan Fang Medical Center, Taipei Medical University, No. 111, Section. 3, Shing Long Road, Taipei 11696, Taiwan.

\section{Acknowledgements}

Winston W. Shen provided valuable editing comments on an earlier version of this manuscript.

\section{Competing interests}

The authors declare that they have no competing interests.

Received: 20 December 2015 Accepted: 26 February 2016

Published online: 10 March 2016

\section{References}

1. Bharti AR, Nally JE, Ricaldi JN, Matthias MA, Diaz MM, Lovett MA, et al. Leptospirosis: a zoonotic disease of global importance. Lancet Infect Dis. 2003;3:757-71.
2. Yang CW, Pan MJ, Wu MS, Chen YM, Tsen YT, Lin CL, et al. Leptospirosis: an ignored cause of acute renal failure in Taiwan. Am J Kidney Dis. 1997;30:840-5.

3. Faucher JF, Hoen B, Estavoyer JM. The management of leptospirosis. Expert Opin Pharmacother. 2004;5:819-27.

4. Farr RW. Leptospirosis. Clin Infect Dis. 1995;21:1-6.

5. Levett PN. Leptospirosis. Clin Microbiol Rev. 2001;14:296-326.

6. Waitkins SA. Leptospirosis. In: Manson-Bhor PEC, Bell DR, editors. Manson's tropical disease. 22nd ed. London: Bailliére Tinadall; 2009. p. 1161-8.

7. Levett PN, Haake DA. Leptospira species (leptospirosis). In: Mandell GL, Bennet JE, Dolin R, editors. Principles and practice of infectious diseases. 7th ed. New York: Churchill Livingstone; 2009. p. 3059-65.

8. Chierakul W, Tientadakul P, Suputtamongkol Y, Wuthiekanun V, Phimda $\mathrm{K}$, Limpaiboon $\mathrm{R}$, et al. Activation of the coagulation cascade in patients with leptospirosis. Clin Infect Dis. 2008;46:254-60.

9. Panicker JN, Mammachan R, Jayakumar RV. Primary neuroleptospirosis. Postgrad Med J. 2001;77:589-90.

10. Wang LS, Wang CC, Huang SH, Chao H, Lin SH, Chang JH, et al. Leptospirosis with transient paraparesis and thrombocytopenia: a case report. J Microbiol Immunol Infect. 2012:45:75-8.

11. Chou YL, Chen CS, Liu CC. Leptospirosis in Taiwan, 2001-2006. Emerg Infect Dis. 2008:14:856-7.

12. Lin PC, Chi CY, Ho MW, Chen CM, Ho CM, Wang JH. Demographic and clinical features of leptospirosis: three-year experience in central Taiwan. J Microbiol Immunol Infect. 2008:41:145-50.

13. Singh P, Gupta AK, Saggar K, Kaur M. Acute disseminated encephalomyelitis subsequent to Leptospira infection. Ann Trop Med Public Health. 2011;:133-5.

14. Bhatia M, Umapathy BL. Deciphering leptospirosis - a diagnostic mystery: an insight. Int J Med Res Health Sci. 2015;4:693-701.

15. Agampodi SB, Matthias MA, Moreno AC, Vinetz JM. Utility of quantitative polymerase chain reaction in leptospirosis diagnosis: association of level of leptospiremia and clinical manifestations in Sri Lanka. Clin Infect Dis. 2012;54(9):1249-55.

16. Waggoner JJ, Balassiano I, Mohamed-Hadley A, Vital-Brazil JM, Sahoo MK, Pinsky BA. Reverse-transcriptase PCR detection of Leptospira: absence of agreement with single-specimen microscopic agglutination testing. PLoS One. 2015;10(7):e0132988. doi:10.1371/journal.pone.0132988.

17. Waggoner JJ, Soda EA, Seibert R, Grant PM, Pinsky BA. Molecular detection of Leptospira in two returned travelers: higher bacterial load in cerebrospinal fluid versus serum or plasma. Am J Trop Med Hyg. 2015. doi:10.4269/ajtmh.15-0174.

18. Wilson MR, Naccache SN, Samayoa E, Biagtan M, Bashir H, Yu G, et al. Actionable diagnosis of neuroleptospirosis by next-generation sequencing. N Engl J Med. 2014;370:2408-17.

\section{Submit your next manuscript to BioMed Central and we will help you at every step:}

- We accept pre-submission inquiries

- Our selector tool helps you to find the most relevant journal

- We provide round the clock customer support

- Convenient online submission

- Thorough peer review

- Inclusion in PubMed and all major indexing services

- Maximum visibility for your research

Submit your manuscript at www.biomedcentral.com/submit
C Biomed Central 